\title{
有效运用读写联动，提升自主阅读能力
}

张华娟

刘海粟小学

DOI:10.32629/jief.v2i6.1061

[摘 要] 阅读作为一种作为基本的获取知识的途径, 其在学生的终身发展历程中发挥着重要的作用。要想使学生在小学阶段就获得语文素养 的发展, 养成良好的语文阅读习惯, 教师需要对学生的自主阅读能力加以培养。自主阅读该理念是以自主学习为基础的, 根据现代教育的有 关要求, 对学生自主阅读的引导, 首先要教给学生有效的阅读方法, 使学生爱上阅读, 在积极地阅读活动参与中获得自主阅读能力的提升。 在本文中，笔者主要就如何在中年级阅读教学活动开展中培养学生的自主阅读能力进行详细说明。

[关键词] 新课标; 小学语文; 自主探究; 阅读教学

中图分类号: G623.2 文献标识码: A

语文课程教学在小学阶段对培养学生的语文修养具有重要作用, 在 小学阶段进行语文教学的主要目的是为了给学生各科学习打下坚实基 础, 所以提高学生的自主学习能力非常关键。阅读能力培养是小学语文 当中的主要教学内容, 在小学阅读练习当中, 通过培养学生的自主阅读 能力, 能够促进学生在课内和课外都能进行自发性的语文学习, 有效提 高学生的学习能力和学习质量。

通过加强小学中年级阶段的语文阅读培养, 可以更好地提高学生语 言表达能力、写作能力, 同时还可以开阔学生视野、拓宽知识面, 让学 生在小学阶段掌握更加丰富的语文知识, 理解更多优美的词句, 提高学 生语文知识的应用能力。通过几年语文学习的积累, 学生到达小学中年 级阶段后, 已经掌握了一定的词汇量, 对阅读的认知和理解处于初级阶 段, 所以在小学中年级提升学生的自主阅读能力效果更为明显, 教师应 注重激发学生对语文的阅读兴趣, 利用学生的阅读积极性, 采取多元化 的教学手段, 树立学生的阅读意识, 培养良好的阅读习惯, 提高学生对 文章的朗读和欣赏能力。

\section{1 小学中高年级语文教学中培养学生自主阅读能力的重要性}

1.1 理解和巩固课上所学知识

培养学生的阅读能力, 有助于加深对课上所学的语文基础知识的理 解。小学生对知识的理解建立在认读文字的基础之上, 教师根据知识储 备, 将课上学到的文字、词语等内容进行概括、分析, 才能让学生理解 其中的含义, 达到巩固知识的目的。在小学语文教学中, 教师对学生理 解力的训练, 是提高阅读能力的关键。

\section{2 提高语文表达能力}

培养学生的阅读能力, 有利于提高语文表达能力。在小学语文教学 过程中, 有能力的语文老师会抓住每一个机会, 让学生在课堂上用自己 的语言对相关的词语、句子进行解释, 概括相关文章或段落的大意, 或 者采取课堂讨论的教学方式让学生在课堂上自由地、充分地表达自己思 考的结果。只有学生具备良好的阅读能力, 才能在课堂上完成老师的要 求, 再通过语言表达将自己的认识有条理地展示出来。

\section{2 小学中高年级语文阅读培养中现存问题的分析}

2.1 阅读资源选择存在局限性
在小学中年级语文教学当中, 一部分教师过于依赖教材进行教学, 将课本内容作为课堂教学的主要依托, 即使引用一些课外文章进行教学, 通常只关注重点段落阅读, 对文章的其他内容一带而过。这种教学方式 导致学生无法更好地开阔语文视野, 因为阅读的文章有限, 也无法更好 地感受语文的魅力, 不利于学生培养良好的语文学习兴趣。在自主阅读 方面学生无法选择更多的文章, 造成教学资源过于局限。

2.2 对自主阅读培养缺乏重视

语文教学受到传统应试教育的影响, 在课程安排方面, 通常更加重 视如何应用课堂测试或者题目练习的方式提高学生的语文成绩, 这就造 成无法给学生创造充足的课余时间让学生自主学习。小学语文教学的进 度和教学方向是由学校主导的, 为了提高升学率, 对考试成绩过度关心, 而忽略了自主阅读能力的培养, 学生在这种环境中学习, 也会忽视自主 阅读能力的重要性。

\section{3 小学中高年级语文自主阅读教学策略}

3.1 指导学习方法, 激发阅读兴趣

兴趣是最好的老师这一点是母庸置疑的。在中年级语文阅读教学活 动开展中, 教师需要立足教学所需, 灵活地运用丰富多彩的教学资源, 激发学生内心对未知的渴望, 借此唤醒其对知识的渴求, 使其产生自主 阅读热情。兴趣决定人们做事的欲望, 所以兴趣作为打开学生自主探究 阅读的大门尤为重要。培养学生产生学习兴趣, 促使学生产生自主探究 学习的动力是阅读教学取得成功的先决条件。导入文章是整个课堂的起 始环节, 该环节占时虽短, 但不可或缺, 为此我们要为学生设计生动的、 有趣味的导入, 将学生的注意力带入文章中。

\section{1 .1 文章背景导入}

众所周知, 每篇文章都有其特定的写作背景, 如作者所写文章使用 的心理背景、社会背景。由于小学生的年龄特点, 小学生最喜欢听故事, 因此教师可将文章背景整理成故事, 用生动幽默的讲述方式传达给学生, 使学生产生对文章的兴趣, 在无形中将学生引入文章中。文章背景的导 入不仅能引起学生的阅读兴趣, 还有助于学生在学习中更好地理解文章, 并产生自己的思想, 从而更好地完成自主学习。

$$
3.1 .2 \text { 设置悬念导入 }
$$


好奇心是每个人少年时期的特性, 教师可以利用学生的这种特性结 合文章内容设置悬念, 使学生产生强烈的学习兴趣和求知欲望。为此, 教师应首先理解文章, 并结合文章设置合理、可靠、能从文章中寻找到 答案的悬念, 调动学生的主动性和积极性, 将学生的兴趣引入文章中。

3.1 .3 运用视觉、听觉创造情景导入

视觉、听觉是人们最直接的感知方式, 人们的心情也常常因为所见 所闻而改变。生动的音乐和直观的图片更能直接触及心灵, 运用音乐和 图片营造符合文章内容的情景氛围, 这种情景再现更能使学生身临其境, 让学生在接下来的学习中更能设身处地地思考文章内容。如在《狼牙山 五壮士》一课中, 可以运用悲壮的音乐和五位先烈的壮举的图片将学生 引入那个战火纷飞的年代, 为学生进入文章中的学习打下情感基础。

3.2 初步阅读, 组内交流

初步阅读只需要学生大致读懂文章内容, 并根据文章内容产生自己 的理解, 并不需要学生在此环节对文章逐字逐句分析。在成功地将学生 注意力引入文章后, 需要学生自主阅读文章, 在阅读文章中, 需要学生 弄清该文章是写景、叙事、写人, 还是抒情。并从文章中找出中心句、 主题句、关键词句, 对其进行标注。在此基础上还要大致弄清文章结构、 写作顺序、写作重点。完成以上初读任务后, 教师根据文章内容提出几 个问题, 学生之间要进行交流思考, 为此我们要为学生创造学习环境, 打造充满趣味的课堂。教师可以自定人数将全班分成小组, 学生先组内 讨论, 合作学习, 鼓励学生针对问题各抒己见, 发表自己的观点, 并倾 听其他同学的观点。学生讨论期间, 教师到每组询问各组内的观点并进 行标注, 这便是所需要为学生讲解的内容。对教师问题的讨论更有助于 调动学生的积极性、参与性, 从讨论中逐渐深入理解文章, 并产生新的 问题再进行新的思考。集思广益的交流更容易培养每个学生用全面的角 度理解观察事物。虽是初读, 但学生对文章的初印象便从这个环节产生。

3.3 解答学生问题, 深层次理解文章

第三个环节也是培养学生自主学习和思考的重要环节。传统的教学 模式只是教师一个人在课堂中发表自己的思想, 教学方式使学生的思维 被限制。在学生初读与组内讨论后, 教师让每组代表讲述本组的问题, 并进行解答。解答不是将问题的答案告诉学生, 教师要以學生为主体, 辅助学生正确理解问题、解决问题, 而不是一概而论, 针对多面性的问 题, 教师应该指导学生从不同角度理解。正所谓仁者见仁智者见智。要 鼓励学生提问题, 问题越多, 学生的思考就越多, 往往提一个问题比解 决一个问题更重要。同时要培养学生的创造性思维, 不唯书唯师的意识。 在这之中要特别注意保护学生的自尊心, 以免打击学生的积极性。

\section{4 写作方式和技巧的教学}

如果将一篇文章看做一个人, 那么文章的内容、中心思想就是人的 心灵与品德, 文章的写作方式和技巧便是人的外貌与装饰。学习一篇文 章不仅要引导学生理解文章内容, 同时还要教学生写作技巧, 一篇好文 章少不了好词好句的装点, 要让学生自己从文章中找出好词佳句, 精彩 片段并摘抄下来, 写于纸上, 记于心中。如一些句子运用的修辞手法、 描写方式和写作句式。而在这个阶段, 教师应教会学生举一反三, 通过 所学文章中的句式, 回想曾经学的相同句式, 便达到了知新后温故的目 的。此外, 还要教会学生运用新学的写作技巧, 可以先模仿、后创作, 在潜移默化中提升学生的内在修养与提升学生自身的写作水平。
3.5 创设情境, 提高学生参与阅读的主动性

情境教学法一直以来都是一线小学语文教师比较青睐的一种教学方 式, 而阅读又是一个内容丰富、形式多样的教学内容, 为情境的创设提 供了很多的素材, 因此, 根据阅读内容和想要达到教学目标的不同, 结 合学生的实际状态创设特定的阅读情境是十分重要的, 有助于学生参与 阅读主动性的提高, 而这样一来, 学生自主阅读的能力也就能得到有效 的培养, 在长期锻炼的过程中得到不同程度的提升。

例如, 我在教学《卖火柴的小女孩》这一内容时, 就利用音乐和视 频画面给学生创设了一个小女孩当时所处的情境, 让学生感同身受, 在 此情境下的阅读, 学生能够更进一步的感受到小女孩的寒冷、恐惧、饥 饿、孤独、痛苦和无助, 有了这样的感觉之后, 在让学生来阅读文章的 具体内容, 学生表现的更加认真, 此时, 在进行相应的指点和帮助, 学 生对 “同情与关爱” 这一主题内容有了更深刻的理解, 自主阅读的能力 也得到了有效的提升。

3.6 鼓励学生进行课外阅读

为了更好地丰富学生语文知识的积累, 拓宽学生的知识面, 在教学 过程中, 教师应鼓励学生进行课外阅读, 进而补充课堂阅读教学中存在 的不足。教师应结合学生的不同兴趣和喜好, 为学生推荐优秀的课外读 物, 在文章选择方面, 需要保证能够适合小学中年级阶段学生的心理, 并且注意对文章阅读难度的控制, 如果文章过于生涩, 学生难于理解; 文章简单, 学生也会失去阅读兴趣, 所以要全面考虑学生阅读能力和水 平进行读物推荐。同时, 在学生进行课外阅读时, 教师还应给予适当的 指导, 让学生在阅读时养成记笔记的良好习惯, 在笔记中可以列出文章 结构、人物、事件和重要词句等, 学生在通读文章之后, 结合笔记内容, 可以更好地理解作品内涵。教师还可以引导学生对文章进行回顾, 从而 对所学到的知识内容加以巩固。在学生欣赏不同类型的文学作品时, 教 师还可以通过穿插适当的文章进行比较, 提高学生的文学审美能力, 体 会个中作品风格和不同的写作表现形式, 从而强化学生自主阅读能力, 为语文写作打下良好基础。

\section{4 结束语}

总之, 在小学中高语文教学中实施自主阅读学习, 可以有效地保证 语文教学工作的有序开展, 提升小学语文的教学质量和效率。同时, 小 学中高年级语文自主性阅读方式还可以提升学生的人文素养。作为一名 小学语文教师, 我们要立足学生实际情况, 不断积累教学经验, 努力提 高学生的积极性, 培养学生语文阅读自主探究能力, 使学生热爱文字、 热爱阅读、热爱写作, 真正爱上语文, 真正成为学习的主人, 进而推动 小学语文教学质量的提升。

\section{[参考文献]}

[1]程军.基于小学语文主题教学实践的方法与策略研究 [J].新课 程,2020(38):6.

[2]郭子豪.提升语文课堂教学效率, 降低学生学习压力 [J].新课 程,2020(38):8.

[3]王瑞琳.新时期先学后教模式在小学语文课堂上的教学分析 [J]. 新课程,2020(38):30. 